\title{
Ciencia, lengua y cultura nacional: La transferencia de la ciencia del lenguaje en Colombia, 1867-1911, de Andrés Jiménez Ángel (2018), Editorial Pontificia Universidad Javeriana, $442 \mathrm{p}$.
}

DOI: 10.17230/co-herencia.17.33.11

\author{
Renán Silva \\ rj.silva33@gmail.com
}

Hace años reseño libros, una tarea que no es fácil, pero que me parece de primera importancia en toda cultura académica que mantenga la idea de que la crítica es elemento constitutivo del conocimiento. Digo que la tarea no es fácil y puedo añadir que la mayor dificultad se encuentra en los libros realmente importantes, de los que no se puede salir de manera rápida con un simple resumen y una o dos anotaciones críticas, como a veces hay que hacerlo con libros que no logran comunicar ningún impulso a la pluma del reseñista. Pero hay libros que plantean las más grandes dificultades, a veces casi que invitando a renunciar a la tarea, en función de sus altísimas calidades. Creo que ese es el caso del libro de Andrés Jiménez Ángel, del que con gran placer he hecho una lectura cuidadosa, pausada, que me ha llevado varios meses y que me ha llevado a borronear una cincuentena de páginas de apuntes con los que al final no he sabido qué hacer. Es un libro del que he aprendido muchísimo sobre historia de Colombia, sobre historia de la lingüística y sobre el propio análisis histórico, tal como se practica en el campo universitario. Un libro que merece por parte de los especialistas no esta simple reseña de quien no es un gran conocedor del tema, sino un amplio estudio crítico de los entendidos en la materia. Por ahora baste con decir que el título no debe engañar y que este libro debería llamar la atención de todos los interesados en la Historia política y cultural del siglo XIX y principios del siglo XX en Colombia, y no solo de los interesados en las ciencias de lenguaje o en la transferencia de modelos culturales. Se trata además de una obra bien escrita, que se puede leer con la confianza de que se van a aprender cosas nuevas, antes no conocidas o no discutidas. 
Aunque el libro resulta difícil de resumir, si se quiere hacer justicia a todo el esfuerzo de trabajo que debe haber significado su investigación y redacción, se puede tratar de señalar por lo menos la importancia del tema, muy bien documentado, y del problema que se ha investigado. Por fortuna el título del libro, y ante todo su subtítulo, brindan un camino seguro para identificar su objeto y propósitos. Creo que, de manera muy precisa, sobre todo su subtítulo señala el punto más elaborado de esta investigación -base de una juiciosa tesis doctoral que cumple con las más altas exigencias de ese género, exigencias que uno empieza ya a extrañar en las tesis doctorales colombianas-

El autor, que conoce bien todo lo que se ha hecho en Colombia y fuera de ella sobre el tema, y que trabajó sobre la base de un riquísimo cuerpo de fuentes primarias, ha producido una obra que desde muchos puntos de vista resulta un modelo para analizar un "caso" de "transferencia científica", y que es al mismo tiempo el estudio de un grupo intelectual reducido, pero significativo -Rufino José Cuervo, Ezequiel Uricoechea y Miguel Antonio Caro son los nombres más destacados, pero no los únicos importantes del grupo de interés-, que fue el actor principal de ese proceso de transferencia y de difusión de nuevos conocimientos. Un proceso que fue, al mismo tiempo, la ocasión de una riquísima experiencia de apropiación y enriquecimiento local, a través de las propias formas de circulación de algunos de los elementos básicos de esa transferencia que constituía una forma nueva de análisis de la lengua, y que encontró réplicas y continuaciones en los libros en elaboraciones locales -con algún nivel menor de elaboración- y en desarrollos pedagógicos concretados en un buen número de textos escolares, si bien este sea un punto sobre el que posiblemente habrá que continuar el camino de búsqueda en el futuro, aunque con lo hecho por ahora en esta obra la tarea parece iniciarse de manera auspiciosa.

La puesta en circulación en el último tercio del siglo XIX en Colombia de lo que desde los primeros años de ese siglo era en Europa (Alemania, Inglaterra y Francia ante todo) la nueva orientación de las ciencias del lenguaje -históricas y comparativas en adelante- fue al mismo tiempo una inmensa aventura intelectual hecha con mucha imaginación y en medio de recursos menos abundantes que aquellos con los que podía contarse en cualquier sociedad europea de ese 
entonces, y fue también el soporte de una opción política centrada en el uso correcto de la lengua, aunque en mi opinión habría que discutir más a fondo si en realidad de manera tan exclusiva como lo afirma la obra, la lengua y sus usos constituyeron el pivote en torno al cual giró toda la acción política conservadora de la nueva orientación de la sociedad, orientación que, en mi opinión, contenía muchos otros elementos, sobre todo de orden económico, fiscal y político, al tiempo que mantenía decisivos elementos de acuerdo con muchas de las conquistas liberales de los años anteriores a lo que se designa de manera tradicional como La Regeneración -por ejemplo, un acuerdo fundamental sobre algo tan determinante como el Código Civil-

Lo que sí queda claro sin mayores discusiones es que a partir de los análisis que ofrece esta obra la narración habitual de la Historia de las ciencias sociales en Colombia deberá ser modificada en muchos puntos, porque la lingüística, ciencia social por excelencia, deberá ser considerada en su carácter de pionera, bien que en investigaciones posteriores habrá que mirar con nuevos cuidados sus elementos de continuidad con el trabajo posterior del Instituto Caro y Cuervo, que me parece por ahora poco valorado, y con la obra en particular de gentes como Luis Flórez, responsable a mediados del siglo Xx de una obra como el ALEC -el Atlas Lingüístico y Etnográfico de Colombia-, obra tan descomunal y discutible como el Diccionario de construcción y régimen de la lengua castellana emprendido por Cuervo, Atlas que, con su recopilación de casi 18 millones de significados de palabras de la lengua castellana en su uso en Colombia, sigue planteando grandes interrogantes sobre su utilidad. Por otra parte, y es un punto para discutir, me parece que en la historia que se nos cuenta en esta obra aparece resuelto de manera muy rápida el problema importante de las relaciones entre descripción de la lengua e imposición de una norma, y creo que las fuentes indican de una manera más tajante que descripción y criterios normativos se encuentran en una tensión que pone de presente que no siempre el nuevo enfoque encontró de manera práctica una realización cumplida de sus propuestas.

Hay dos o tres observaciones críticas que quisiera arriesgar en los renglones siguientes, sin que ellas resten ningún valor a este importante trabajo, presentado por lo demás en una pulcrísima edición, sobre la cual no hay queja ninguna que se pueda manifestar. 
La primera de esas observaciones tiene que ver con lo que parece ser un defecto constitutivo de las tesis doctorales en todas partes, y que recuerda cierta desmedida exigencia de los directores de tesis, una patología que resulta pronto asimilada por sus discípulos. Se trata del "mal del contextualismo", una manía que impone la idea de que los trabajos de historia necesitan de unos "contextos" enciclopédicos que generalmente exceden la propia lógica del problema estudiado, un "contexto" termina siendo al final un elemento que no logra un real punto de entronque con el objeto principal del que se ocupa el trabajo, por fuera de ser construido sobre la base de fuentes secundarias no siempre de la mejor calidad. Se agrega a lo anterior el recurso a ciertas orientaciones de enfoque que pueden ser una fuente de malas apreciaciones. En esta obra me refiero en particular a la idea de que hay "proyectos" y "contraproyectos", muy definidos, poco cambiantes en su trayectoria y no sometidos a la incertidumbre de sucesos posteriores que no se podían imaginar por adelantado. Para el autor del libro hay un "proyecto liberal" dominante a mediados del siglo XIX y hay en oposición a él un "contraproyecto conservador" que se le enfrentará a la manera de dos púgiles en un cuadrilátero, sin ninguna posibilidad para el analista y para el lector de imaginar un mundo social y político más cercano a lo inestable, a las definiciones de última hora, a las circunstancias cambiantes, a la invención, a los encuentros de palabras y de giros de lengua que no se pueden entender en su formación sino en la marcha misma de los acontecimientos.

Pienso también que en el libro hay una suposición no discutida que asume la existencia de realidades que no existían en los años finales del siglo XIX, y ni siquiera en los primeros años del siglo xx. Me refiero a la idea de que en Colombia había en ese entonces un mercado del libro ya constituido -una de las condiciones de la transferencia de ciencia hacia los grupos más significativos de la sociedad, si se trata de postular que los ideales del "bien hablar" y la pasión por la gramática llegaron a la "sociedad popular", un punto que me parece difícil de demostrar. El autor del libro conoce bien la obra de José Manuel Groot, y por lo tanto sabe de los desastres que lo persiguieron en los intentos de venta de su obra, de la que se supone que era foco orientador del "proyecto conservador", como promotora de una cierta visión 
del pasado colonial y nacional. Ni los sermones entusiastas de los párrocos antioqueños sirvieron de mucho para que Groot se pudiera desprender de la edición de su obra, que nunca logró vender en un "mercado libre", como se sabe por su propia correspondencia. Otro tanto puede decirse acerca de la idea de la existencia en esa época de un "sistema educativo", expresión que vuelve una y otra vez en la pluma del autor. Creo que los datos de difusión de la escuela como práctica organizada en el siglo XIX y a principios del siglo XX, lo mismo que los datos sobre avances del alfabetismo que se conocen para Colombia en esa época, algunos de los cuales se citan en la obra, indican una realidad escolar menos estructurada y más incipiente, e invitan a dejar de lado esas categorías, que son realmente engañosas, para pensar más bien en lo contrario, es decir, en que la ausencia de ese "sistema" -forma estructural que tiene un sentido preciso en ciencias sociales-, tal vez fue una de las condiciones que limitaron la posibilidad de una gran lengua nacional "bien hablada" por todos los colombianos, y no solo por los hombres de letras. Por lo demás, muchos datos invitan a considerar la hipótesis de que fue en el período que va de 1920 a 1940, en el momento del surgimiento más estable de las escuelas normales medias y superior, cuando la difusión del ideal de la corrección en la lectura y la escritura logró por primera vez, y por un número breve de años, su mayor impulso como realidad práctica.

Igualmente, aunque en otra dirección, creo que un punto problemático de los análisis que presenta la obra tiene que ver con el uso intencionalista y racionalista que se hace de la noción sociológica de "estrategia". Todo el trabajo de ciencia y de difusión de ciencia del grupo central que se comprometió en la tarea de renovar el análisis de la lengua en el último tercio del siglo XIX y principios del siglo XX - para incluir a don Marco Fidel Suárez- termina siendo presentado como un esfuerzo para "posicionarse", utilizo la palabra que usa el autor, en el campo de los intelectuales legítimos y de autoridad dominante en la sociedad. Concedamos que ese puede haber sido el resultado de su trabajo. Pero me parece difícil convertirlo en una intención previa. Y ello sobre todo porque bajo esa forma todo el esfuerzo auténtico de ciencia de gentes como Rufino José Cuervo y Ezequiel Uricoechea, todo su inmenso deseo de saber y su gusto por el 
conocimiento, con todo el sacrificio que al mismo tiempo comportó -con su cuota de soledad y de separación social y familiar, como en el caso de Cuervo-, termina siendo considerado como una "estrategia de posicionamiento", lo que anula mucha de la importancia y de la grandeza de esos intelectuales, sobre todo de Cuervo y de Uricoechea, y vuelve invisible toda la capacidad de locura y de aventura que fueron capaces de desplegar por el mundo, una ausencia que no debe ser ajena al hecho de que esta gran obra poco hace reír, no se permite nunca un gesto de humor en el examen de trayectorias intelectuales que se dejan ver en muchas de las cosas que se nos cuentan, impidiendo ver la sombra de ironía quijotesca que recorre todos esos episodios de ciencia en torno a la constitución de la nueva disciplina, o mejor, a su "aclimatación" por parte de los intelectuales gramáticos. Es por eso tal vez por lo que durante la lectura de la obra muchas veces pensé que el único título que podría faltar dentro de esa completísima bibliografía que se cita era El cuervo blanco, de Fernando Vallejo, que apareció en abril de 2012, una obra desde luego de otro orden, pero de una gran erudición, que por ejemplo le hubiera permitido al autor precisar muchas cosas sobre la circulación de algunas de las obras de Cuervo, pero sobre todo poder observar un tratamiento de Cuervo y de los gramáticos colombianos realizada con irreverencia y humor, aunque con admiración, respeto y justicia.

Una observación final, que es una impresión mía como lector, y que tiene antes que todo una perspectiva historiográfica, que va más allá de esta importante obra, es la siguiente: el libro que reseñamos es extraordinariamente cuidadoso en señalar que el llamado proyecto conservador de la lengua correcta, si bien fue obra principalmente de intelectuales adscritos al partido conservador, en realidad comprometió en su despliegue, en su formación y en sus etapas de difusión a hombres de letras que pertenecían a los dos partidos, liberal y conservador. La obra hace gala todo el tiempo de ese cuidado, y utiliza todos los recursos de lenguaje posibles para dejarlo en claro, y ello para todos los sucesos que examina, desde la amistad misma de Rufino José Cuervo, hombre formalmente conservador, con Ezequiel Uricoechea, un señor de temperamento muy liberal, hasta la fundación misma de la Academia de la Lengua, obra de gentes de las "dos colectividades históricas". Pero igualmente en el 
caso de las publicaciones periódicas que alentaron los "intelectuales gramáticos", en las iniciativas pedagógicas que sostuvieron, en las instituciones escolares que crearon, y en el propio cultivo de la lengua considerada correcta: aun a principios del siglo $\mathrm{xx}$, desde Londres, Santiago Pérez consultaba a su amigo Cuervo una duda sobre nuestra "señora gramática", como decía Cuervo a veces, sin olvidar que muchos años antes Rafael Uribe Uribe había escrito un Diccionario abreviado de galicismos, provincialismos y correcciones de lenguaje, que dedicó "Al eminente filólogo y lingüista Rufino José Cuervo". Llegados a ese punto de los matices, de los multiplicados adverbios para decir que sí, que el "proyecto era conservador principalmente", pero "que no únicamente", "ni exclusivamente", etcétera, uno puede preguntarse si no resulta ya más adecuado abandonar ese terreno de los multiplicados matices y plantearse que lo que estamos necesitando es un grupo de hipótesis diferentes para poder imaginar, de otra manera, esa forma de relación entre política y cultura de los hombres de letras de esos años, pues todo indica que la forma habitual de plantearse el problema parece no servir, como lo prueba la necesidad constante de modular, matizar, de una manera que al final no se sabe bien qué es lo que afirmamos $\mathbf{I}$ 